\title{
eProject User Experience: The Reality
}

\author{
doi:10.3991/ijac.v3i4.1469 \\ John Sandler \\ Telstra Corporation, Melbourne, Australia
}

\begin{abstract}
Corporate eProjects have become fast-paced and increasingly demanding. More often than not, problems and challenges readily surface within technology projects. These can often stem from poor us ability and user e xperience aspects of the development process, together with lack of ad equate communications plans and strategies.
\end{abstract}

Successful forward planning and succinct on-going c ommunication of development and testing processes is critical.

Clear communications acros s the ran ge of impacted u ser work grou ps, t ogether with the p roject tea $m$, en suring an understanding of all rol es in th e d evelopment $p$ rocess is vital. Understanding $t$ he need to engage expert users and representatives from the impacted user groups is also critical.

This paper and associated presentation will look at what can happen in the real world, when even highly detailed project planning $c$ an be undermined by a lack of communications, understanding and un satisfactory project te am user experience. In effect, the user experience of project teams.

Index Terms-project, user ex perience, usability, communications, user-centred.

\section{Project Design AND PlanNing}

The project startup phase is crucial, because this is when the key resources forming the critical mass of the project team are brought together.

Project teams are increasingly becoming "virtual“teams. Project team members often are not together in one location and it is not unusual for them to be thousands of kilometres apart, working in different geographic and time zones.

Test Manager, Test Analyst, Usability specialist, Instructional Designer, and others are roles that are critical to the on-going success of any application development project.

The Project Manager must ensure that there is transparency of roles across the project team, and that there is an on-going fluid synergy between and across all project team members. There is the risk that each person(s) in their respective role gives their own interpretation of what they think is needed to bring the project to fruition.

From this, misinterpretations can be created from the start and the time line of the tasks and the roles associated are skewed to favour the individual creating the time line. (e.g., the project manager in this case) As a result, the project has the potential to not fully meet the needs of all involved.

By making everyone fully aware of their own roles, misinterpretations can be kept to a minimum and the tasks and roles will be associated appropriately.
Once everyone is aware of the roles of a project, there should be a clear idea of what's involved from all parties and a better understanding of which team members are person(s) is responsible for specific tasks and activities, based on their skill sets.

This makes the communications process within project teams even more critical to ensure that all project team members are constantly apprised of any technical or other issues that may impact on application interface development, project deliverables, and timelines.

To facilitate the understanding of project team roles and responsibilities, as well as users, stakeholders and development team members, a process of information gathering should be undertaken.

\section{A. Information Gathering}

A process of information gathering or discovery needs to be undertaken. Information needs to be collected and from the organization and stakeholders of the project.

The project needs to find out as much as possible about the target user group/s:

- Who are the current and future impacted users?

- What are their workplace/environmental routines?

- What are their expectations \& needs?

- Observation, consultation in the context of location where application will be used

- Observe and understand user tasks and activities

This knowledge will offer greater insight into user behaviours, habits, preferences, likes, and dislikes

This will give a greater understanding of how they use, or may use, both the application and any materials associated with it.

\section{TeChNOLOgY DeliVery PROCESSES}

Most technology organizations develop their projects with the aid of a Technology Delivery Process, as seen in Figs. 1 and 2, illustrating the high level and detailed views. TDP is a suite of processes and supporting process aids (e.g. templates, checklists, reviews and guidelines) used to develop and deliver quality products and services and maintain them.

Major organizations that I have consulted to in Australia, such as Coles Myer, IBM and Telstra, all employ a version of TDP.

The TDP process is flexible so it can be tailored for groups who already have processes; and it is benchmarked against and based on the CMMI (Capability Maturity Model Integration) 'best practice' model.

(CMMI) is a process improvement approach that helps organizations improve their performance. CMMI can be used to guide process improvement across a project, a division, or an entire organization. 


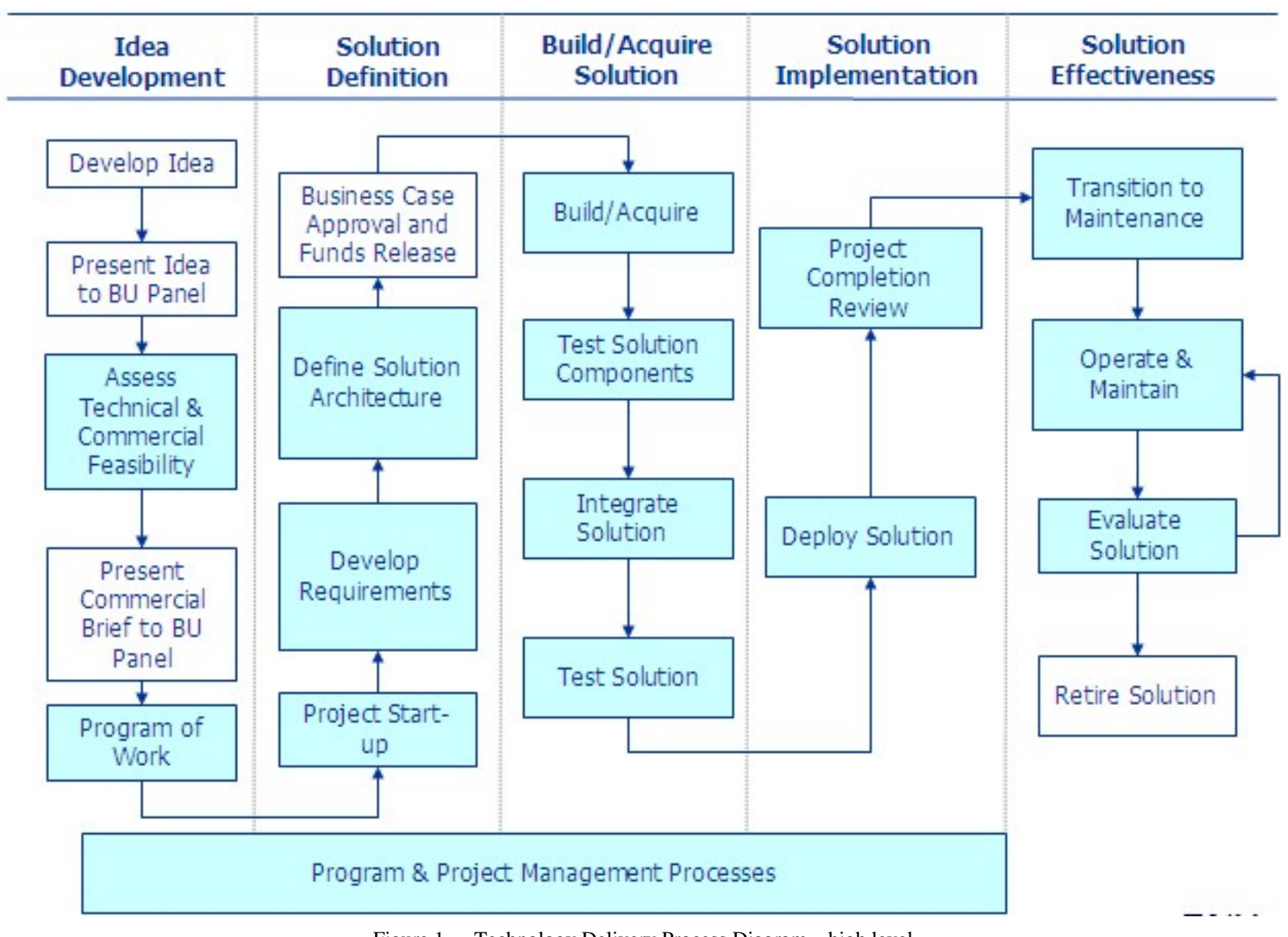

Figure 1. Technology Delivery Process Diagram - high level

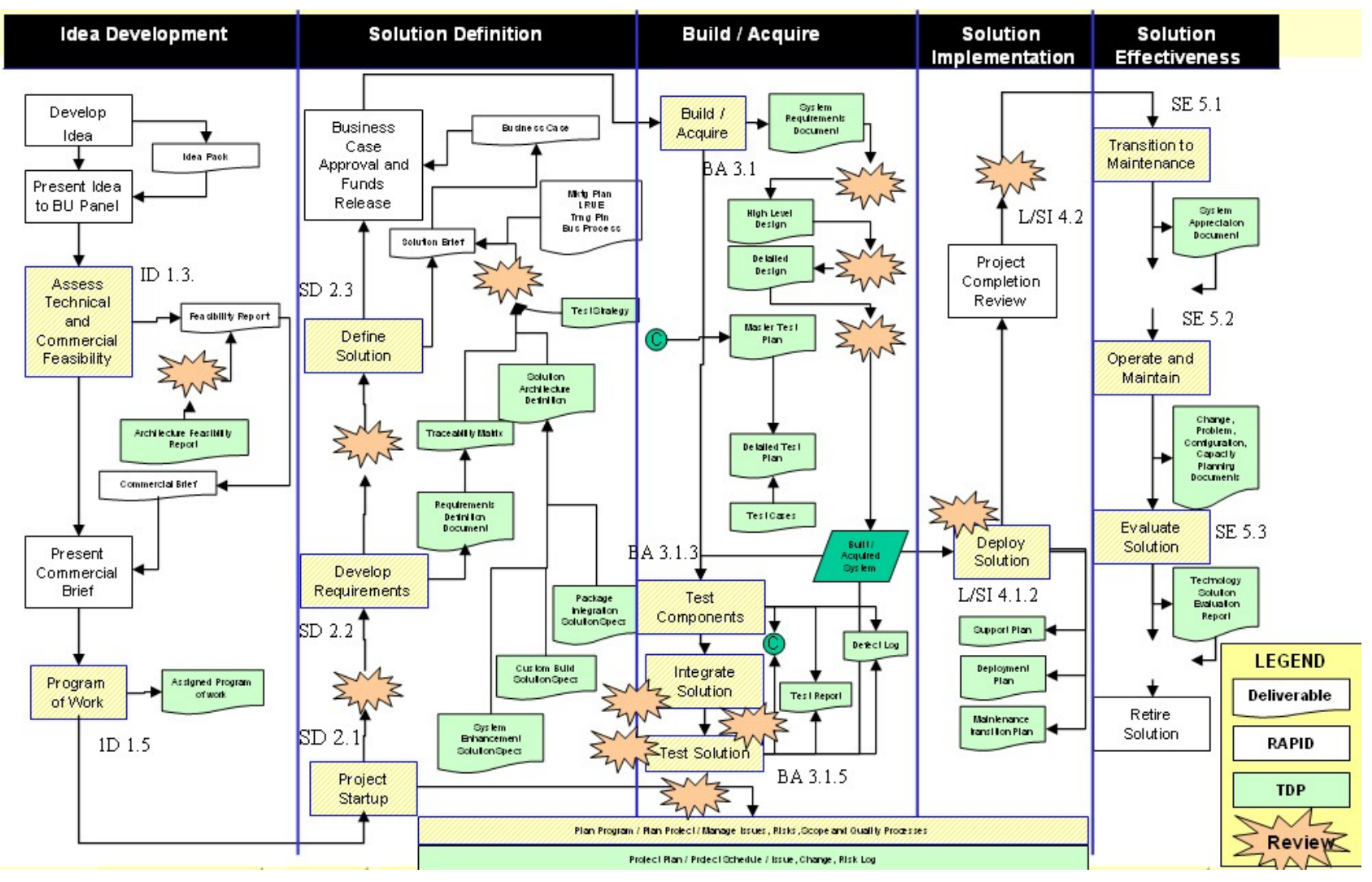

Figure 2. Technology Delivery Process Diagram - detailed 
However, a poor or lack of a communications strategy, particularly for the project team, can create frustrations due to lack of role clarity, and in particular clarity regarding application and graphic user interface development, and who (in the project team) is responsible for the specific aspects of various deliverables.

This aspect of the project user experience is generally overlooked in the planning stages, and it is vital that these aspects are addressed during the Project Design phase.

\section{USER CENTRED DESIGN}

The role of the User Centered Design (UCD) process is vital to the success of site and/or application development, and certainly vital to the success of project user experience, yet it remains something of a foreign concept.

It is frequently bundled in with "Usability" and tacked on to the end of a project instead of taking its proper place as the underlying foundation.

User-Centered Design is a process focused on the design of information/tools that cater to the end user for the purposes of the most effective and efficient way of maximizing usage.

UCD is about designing the total user experience, consisting of all aspects of a product or service as perceived by users; and incorporating the most effective and efficient way of maximizing usage.

It is critical to setup and incorporate a number of important process steps at the project planning stage, and monitor and maintain the validity of these steps throughout the project.

The following major process steps and their associated tasks are an inherent part of the User-Centered Design process, and without continually obtaining, revising, validating and incorporating user-based requirements, the project will have declining chances of success.

\section{UsABILITY}

Usability is a crucial component of the User-Centered Design process. What is usability?

Definitions vary - we basically tend to think it is about how successfully a user can navigate and interact with a web site or application to achieve their goal or goals either personal or workplace-based.

These goals could range from finding information; making a retail transaction, ordering items; manufacturing; personal needs; or merchandising activities.

Usability is also about how easy a product or application is to use.

The usability of applications can be considered successful if users can navigate and use them as tools to achieve their specific workplace performance requirements.
Successful applications should meet user needs, be easy to access and intuitive to navigate.

- From the user's perspective usability is important because it can make the difference between gaining the knowledge to perform a task accurately and completely or not, and enjoying the process; or being frustrated.

- From the developer's perspective usability is important because it can mean the difference between the success and failure of a system.

- From a management point of view, software with poor usability can reduce the productivity of the workforce to a level of performance worse than without the system.

- From the project team perspective, their user experience, that is, combining effectively towards the creation and deployment of a user-friendly product, needs to progress smoothly.

The excellent site www.usability.gov, as illustrated in Figs. 3 and 4, provides a wealth of information for planning projects to cater for usability and user centred design requirements.

A successful project team user experience will only occur if the communications strategy is implemented effectively. This means ensuring that all members of the project team are involved in regular team meetings and updates from all members.

It is important to understand all the stakeholders for your product: the principals who make the purchasing decision, the business partners, technicians, developers, and consultants who are responsible for installing and configuring your product and bringing it to market, the users who will interact with the product, and of course the project development team.

Although you may have some representative stakeholders or proxies on your design team, it is also important to communicate this stakeholder information to everyone on the project team.

\section{WHEN THINGS GO WRONG}

When a project has not been carefully planned, or even if it has but has a project manager who is not project team -centric, but has a project plan focus; this scenario becomes a recipe for confusion, frustration and timeslipping.

I have recently completed a role in a project where problems that arose from lack of communications within the project development team began to manifest themselves at the testing stage.

The development streams of the project had been proceeding on time, but then technical problems started happening just prior to the testing stage.

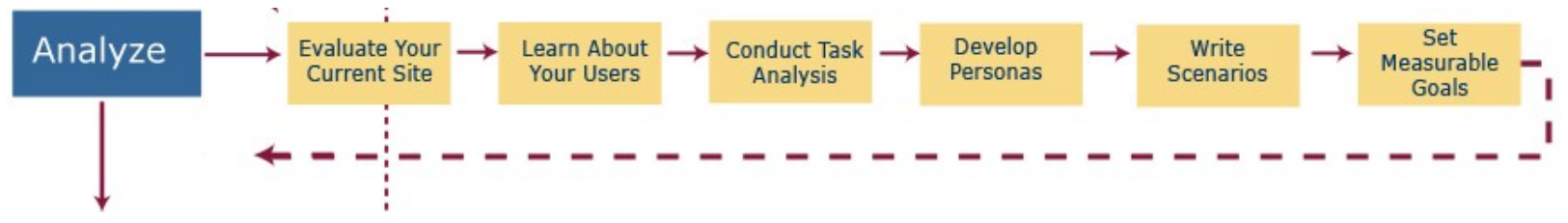

Figure 3. Analyze component - step by step guide 


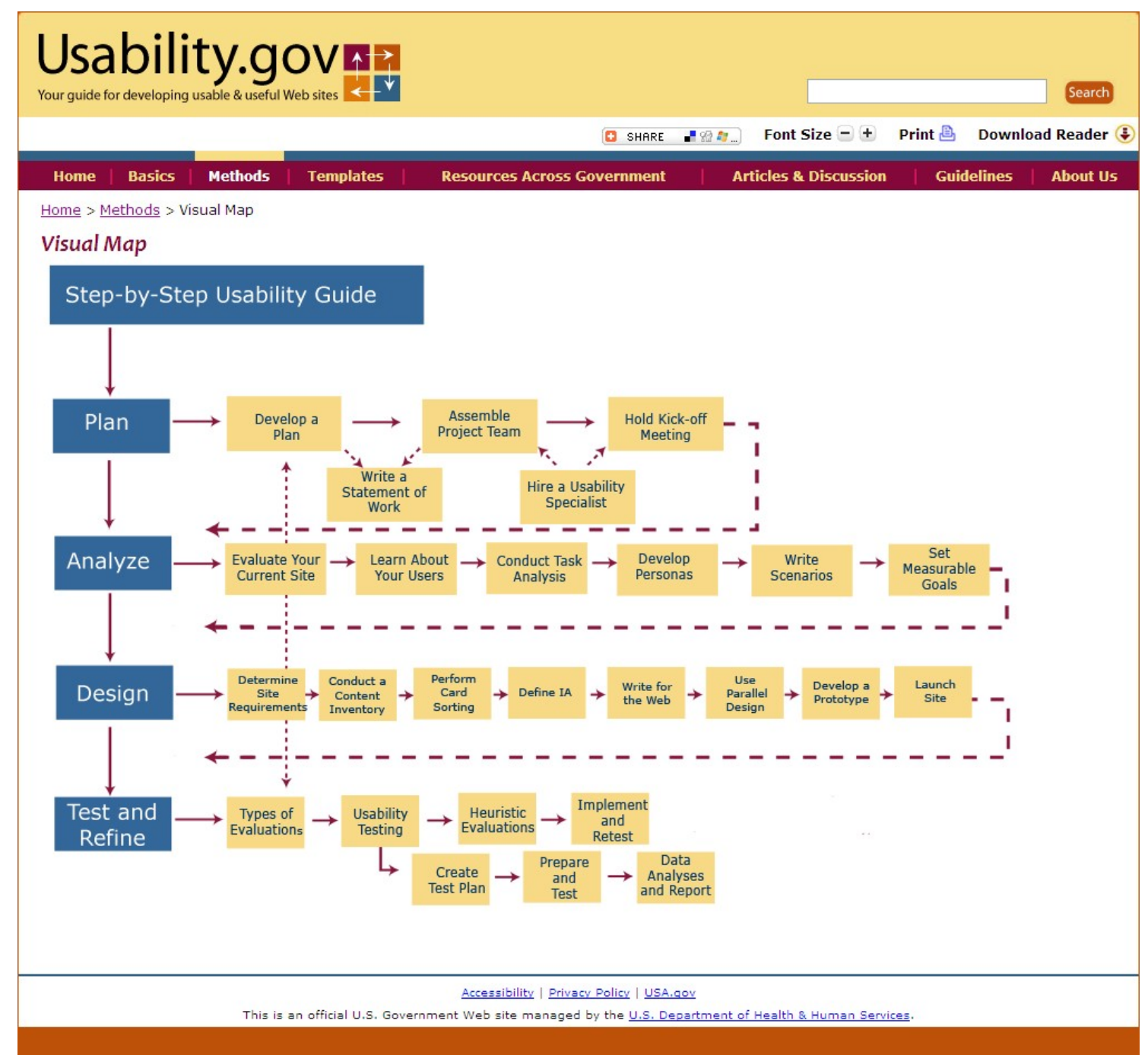

Figure 4. Usability process planning from Usability.gov

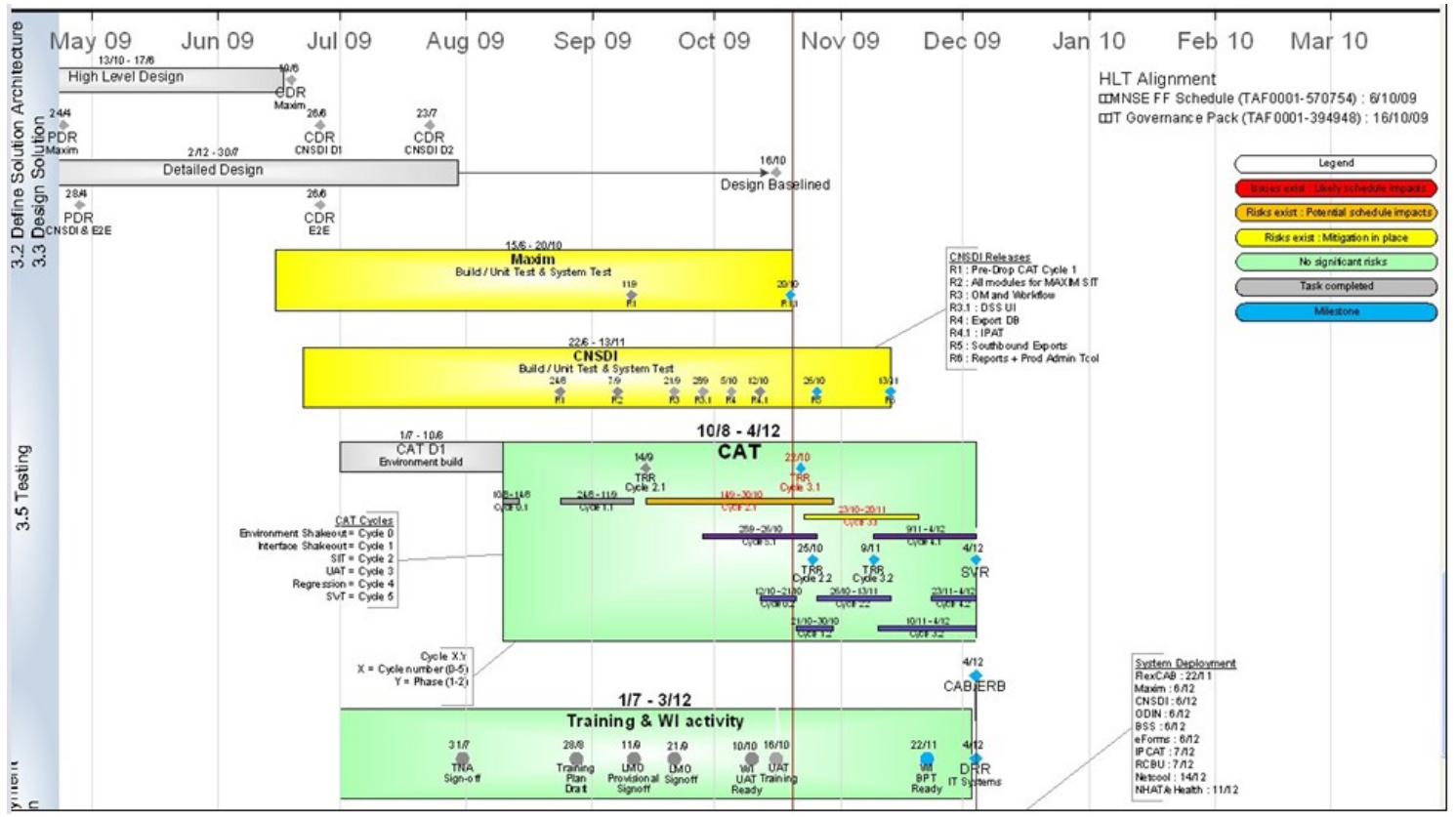

Figure 5. BPT (Business Process Trial) 
Timelines and milestones planned as part of the Business Process Trial (BPT), as seen in Fig. 5, had to been reassessed and altered. But this was a regular iterative process.

However, the real issue and concern that became apparent at this stage was that there had been a breakdown in the testing schedule of consultations and interviews with stakeholders.

\section{A. Testing}

Testers were not being included the iterative prototyping and development stages, and were being left out the development loop. This meant that the information scripted into a series of Test Cases, as seen in Fig.6, did not truly reflect all stakeholder requirements.

Typically, the testing team meets with the rest of the project team and appropriate stakeholders to decide on the major elements of the test plan and strategy. Often, the usability specialist then drafts the plan, which circulates to management and the rest of the project team.

Once everyone has commented and a final plan is negotiated, the usability specialist revises the written plan to reflect the final decisions.

The testing schedule in general is well planned by this stage of a project. The testing schedule should have had iterative changes made, and the Test Plan completed.

The purpose of the Test Plan is to document test activities that will happen, how the test will be conducted, what metrics are going to be captured, number of participants to be tested, and what scenarios and evaluation criteria will be used, detailing the intricate aspects of a project testing phase.

The Test Plan should be understood and agreed to by all parties and signed off so that testing activities can commence.
When one of the testers came asking for assistance with navigating the User Interface, this was evidence that there were problems.

The tester couldn't find the links to new Analytic screens for the Reporting module, a critical business enhancement for the new system, as seen in Fig. 7. This was because the various Reports were accessed by drilling down from the Answers tab. This change had not been communicated to the Testing team.

If the communications strategy had been properly implemented, this situation would not have occurred; and the testing team would have been aware of the limitations of the navigational User Interface being developed by the $3^{\text {rd }}$ party vendor.

\section{SUMMARY}

Successful forward planning and succinct on-going communication regarding application development and testing processes is critical.

Clear communications across the range of impacted user work groups and ensuring that they understand their roles in the development process is vital. As is the need to engage expert users and representatives from the impacted user groups.

Together with appropriate product briefs and regular internal communications releases, regular team meetings, and workshops if required, will ensure that all involved understand 'what to do', and what updates are planned to the User Interface.

Project usability can be considered successful if project team members have a clear understanding of their role in the project, meaning that they also have a clear overview across the entire project, not just their portion in isolation.

\begin{tabular}{|c|c|c|c|c|c|}
\hline \multirow[t]{2}{*}{ Objective ID } & \multirow[t]{2}{*}{ Test Case Name } & \multirow[t]{2}{*}{ Objective } & \multirow[t]{2}{*}{ Evaluation Criteria } & \multicolumn{2}{|c|}{ Doc. Ref. } \\
\hline & & & & RDD & BS \\
\hline TO-E2E-01 & $\begin{array}{l}\text { Quote \& Order } \\
\text { new MNS } \\
\text { solution (MNS } \\
\text { Bundle only - } \\
\text { 3G backup) }\end{array}$ & $\begin{array}{l}\text { To evaluate process flow } \\
\text { \& solution capability } \\
\text { required to support orders } \\
\text { that only contain MNS } \\
\text { Standard Product } \\
\text { Bundles. }\end{array}$ & $\begin{array}{l}\text { 1. Qualified quote is } \\
\text { created in the system for } \\
\text { presenting to the } \\
\text { customer. It contains the } \\
\text { product landscape and the } \\
\text { price customer is going to } \\
\text { pay. } \\
\text { 2. Orders have been } \\
\text { created. } \\
\text { 3. All product (including } \\
\text { configuration attributes), } \\
\text { service, pricing details and } \\
\text { delivery information have } \\
\text { been finalised. } \\
4 . \text { Assets are created in } \\
\text { Maxim. }\end{array}$ & $\begin{array}{l}\text { TA01 } \\
\text { TA03 } \\
\text { TA06 } \\
\text { TA10 } \\
\text { TA11 } \\
\text { TA02 } \\
\text { TA12 }\end{array}$ & $\begin{array}{l}\text { BS1 } \\
\text { BS5 } \\
\text { BS7 }\end{array}$ \\
\hline
\end{tabular}

Figure 6. BPT Test Case details 


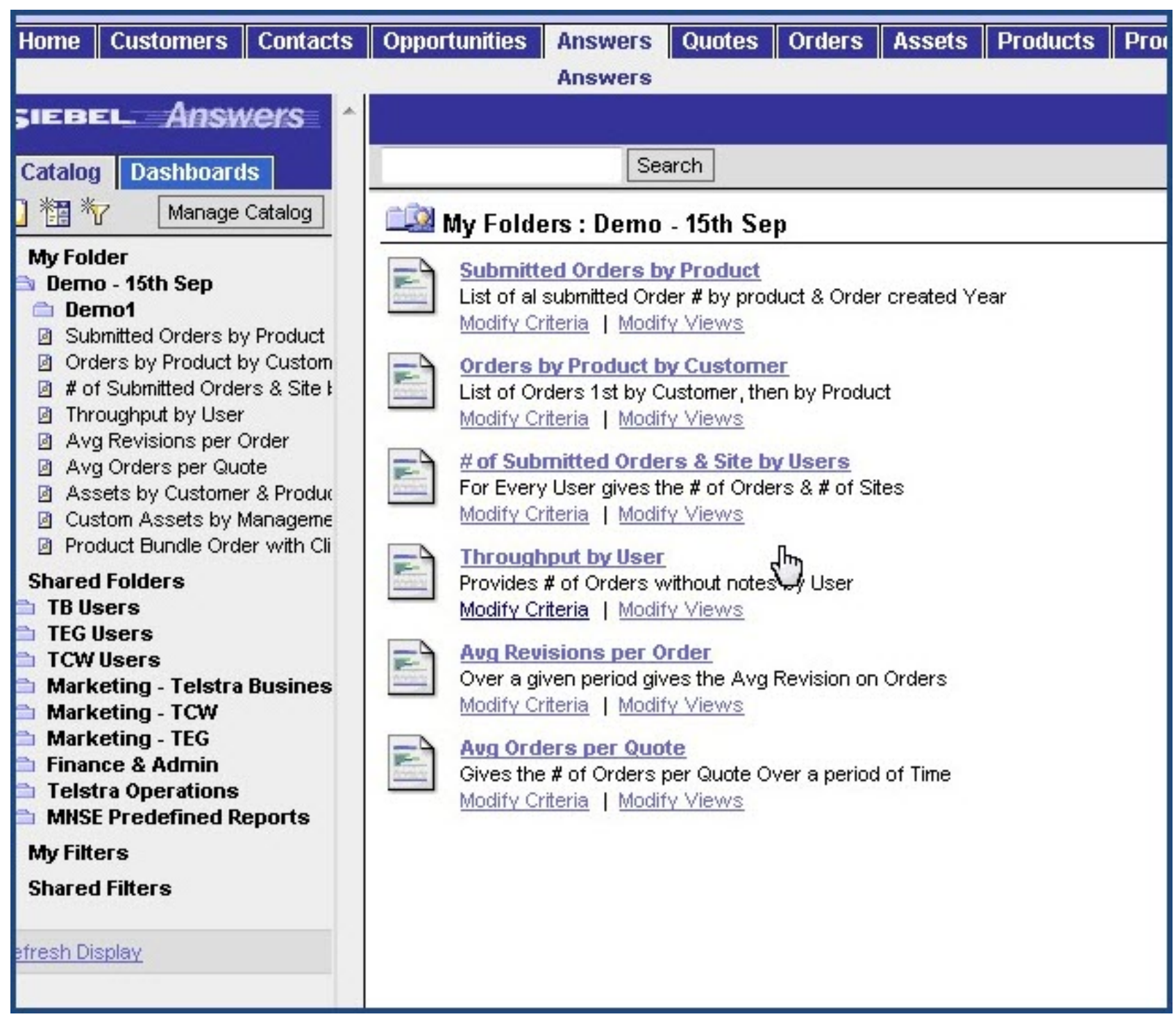

Figure 7. Reporting screen with confusing menus

\section{REFERENCES}

[1] Sandler, John "Project Usability: Schmoosability...what does it matter?” ICLEW 20010 Proceedings, New York, NY, USA, June 2010.

[2] Sandler, John "The Usability of eLearning: Designing for effective performance or not,” ICLEW 2009 Proceedings, New York, NY, USA, June 2009.

[3] Sandler, John "Developing Telecommunications eLearning modules: Flexible performance support” ICL 2008 Proceedings, Villach, Austria, September 2008.

[4] http://accessites.org/site/2008/06/user-centered-design-andusability-its-role-in-a-project/

[5] Sandler, John "Scenarios and Profiling for Useful and Usable Web Sites,” ForUse 2002, Proceedings First International Conference on Usage-Centered, Task-Centered and Performance-Centered Design pp. 25-38, Portsmouth USA, August 2002.

[6] Goto, K., and Cotler, E. (2002) Web Redesign: Workflow that Works. Indianapolis: New Riders
[7] Donoghue, K. (2002) Built For Use. New York: McGraw-Hill.

[8] Krug, S. (2000) Don’t make me think! Indianapolis: New Riders.

[9] Seigel, D (1999) Futurize Your Enterprise. New York: Wiley.

[10] Snyder, Carolyn, "Using Paper Prototypes to Manage Risk," October 1996, Software Design and Publisher Magazine

[11] http://www.usability.gov/methods/process.html

[12] http://blog.usability.gov/

[13] https://www-01.ibm.com/software/ucd/agileuxd.html

\section{AUTHOR}

John Sandler is a freelance instructional designer and usability consultant who contracts to telephony technology projects for Telstra Corporation, Australia. (e-mail: johnsandler@ fastmail.fm).

Submitted August $28^{\text {th }}$, 2010. Published as resubmitted by the authors October $17^{\text {th }}, 2010$. 